\title{
Artificial Intelligence Techniques for Modelling of Temperature in the Metal Cutting Process
}

\author{
Dejan Tanikić and Vladimir Despotović \\ Additional information is available at the end of the chapter
}

http://dx.doi.org/10.5772/47850

\section{Introduction}

The heat generation in the cutting zone occurs as a result of the work done in metal cutting process, which is consumed in plastic deformation of the cutting layer and overcoming of friction, that occurs on the contact area of the cutting tool (i.e. cutting insert) and work material (i.e. workpiece). The heat generated in the chip forming zone directly influences the quality and accuracy of the machined surface. The negative occurrences in the metal cutting process, such as: Built Up Edge (BUE) formation, workhardening, plastic deformation of the cutting edge, deformation of the workpiece, etc. are also dependent on the heat.

Modelling of temperature in the metal cutting process is very important step in understanding and analysis of the metal cutting process. In order to model the temperature which occurs in the chip forming zone, large number of experiments must be carried out at different cutting conditions, synchronously measuring the chip's top temperature using the infrared camera. The infrared method gives a relatively good indication of the measured temperature, comparing with other methods for temperature measurement, such as: thermocouples, radiation methods, metallographic methods etc.

In recent years the research in the area of process modelling is directed on the use of systems based on artificial intelligence: artificial neural networks, fuzzy logic systems, genetic algorithms, as well as combination of mentioned systems. Results obtained in the first phase will be used for modelling of the cutting temperature using the response surface methodology model (RSM model), feed forward artificial neural networks (ANN model), radial basis function network (RBFN model), generalized regression neural 
network (GRNN model) and adaptive neuro-fuzzy system (NF model). The accuracy of the proposed models will be presented, as well as their suitability for use in concrete problems.

Analysis and modelling of the metal cutting process can be very useful in determining of the optimal values of input process parameters (cutting speed, depth of cut and feed rate). Positive effects could be many. The quality of the machined surface can be enhanced and tool life can be extended, leading to advancement of the production economy.

\section{Metal cutting process temperature}

Cutting temperature affects changes in the workpiece material, and consequently, the quality of the machined surface. It also influences changes in cutting tool material and plays an important role in tool wear. Chip temperature might be used to investigate the friction behaviour of cutting tools, because this temperature is dependent on the friction energy which is entering the chip at the rake face.

The amount of the heat generated in the metal cutting process is expressed through the work done in the process and the mechanical equivalent of the heat (Arshinov \& Alekseev, 1979), in the form:

$$
Q=\frac{F_{z} v}{E}
$$

where: $Q$ - amount of the heat generated in the metal cutting process, $F_{z} v$ - work done in the process, $E$ - mechanical equivalent of heat

The heat balance during the metal cutting process can be expressed as follows:

$$
Q=Q_{1}+Q_{2}+Q_{3}+Q_{4}
$$

where: $Q$ - total amount of heat generated in cutting, $Q_{1}$ - amount of heat carried away in the chips, $Q_{2}$ - amount of heat remaining in the cutting tool, $Q_{3}$ - amount of heat passing into the workpiece, $Q_{4}$ - amount of heat radiated to the surrounding air

According to the empirical investigations, $60-86 \%$ of the heat is carried away in the chips and grows with increase in cutting speed. For lathe operations this proportion is as follows: $50-86 \%$ of the heat is removed in the chip, $10-40 \%$ remains in the cutting tool, $3-9 \%$ left in the workpiece and about $1 \%$ radiates into the surrounding air.

A large number of factors affect the quantity of heat generated. The most important ones are: the cutting speed and the cutting depth (Tanikić et al., 2010a). It is also noticed that there is more heat transferred into the workpiece in the finishing turning than in the rough turning. Theoretically, there are three zones of the heat generation that can be identified during turning (Fig. 1.) (Tanikić et al., 2010b): 
- cutting zone

- tool-chip contact zone

- tool-workpiece contact zone

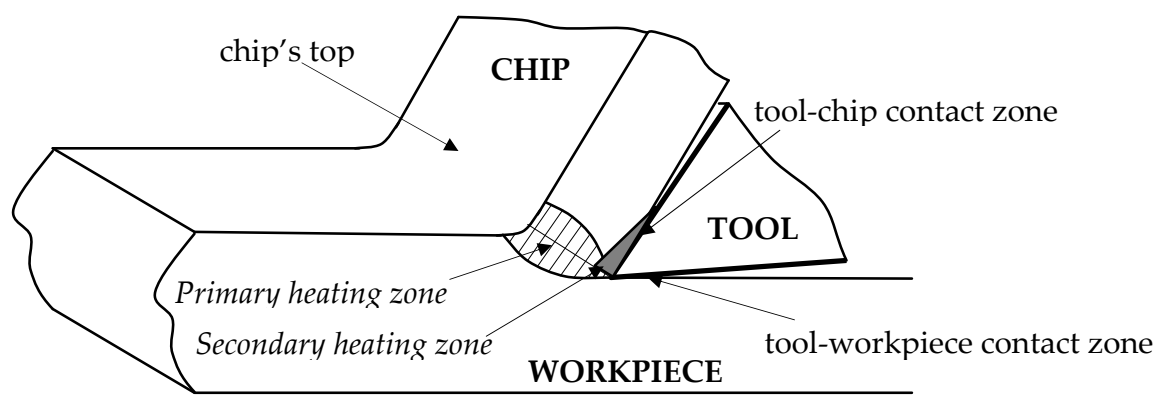

Figure 1. Heat generation zones during metal cutting process

The temperature of the various points of cutting tool, chip and workpiece are different, as shown in Fig. 2. (Arshinov \& Alekseev, 1979). Temperature of the layers close to the cutting tool surface is higher than those away from it. The highest temperature, as expected, occurs at the point of cutting tool - workpiece contact (denoted with $\mathrm{T}$ on Fig. 2.), while the temperature of the other points are given as proportion of this temperature.
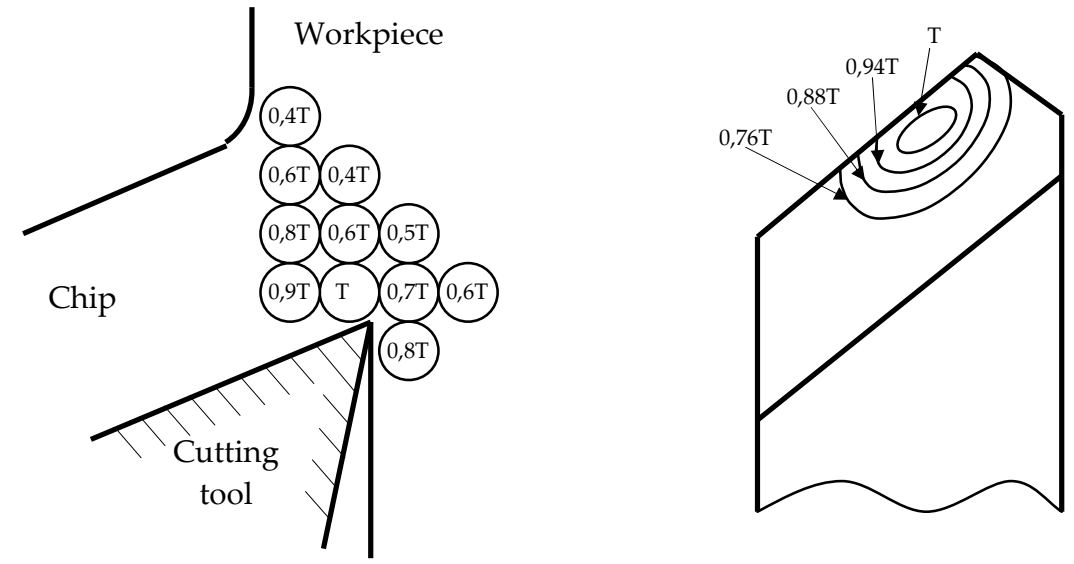

Figure 2. Temperature distribution in the cutting tool, chip and workpiece

\subsection{Factors influencing cutting temperature}

Factors which directly influence cutting temperature, as well as chip temperature, during metal cutting process are: type of workpiece material, cutting regimes (cutting speed, feed rate and depth of cut), dimensions and geometric characteristics of cutting tool, quantity and pressure of the coolant fluid etc. Recent investigations show that bar diameter also influences cutting temperature (Boud, 2007). 
Workpiece material - In general, the greater amount of heat is generated during cutting steels when compared to cast iron. Cast irons also have lower thermal conductivity than steels. The high pressure on the peak of cutting tool during cutting cast iron causes short and broken chips. Mechanical properties of the workpiece material affect cutting temperature significantly. The higher the tensile strength and hardness of the workpiece, the greater the resistance force that must be overcomed during cutting, i.e. the more work is required to be done, resulting in higher cutting temperatures. On the other hand, the higher thermal conductivity and heat capacity of the workpiece, the higher the level of the heat transfered from the place where it is generated into the chip and the workpiece. At the same time there is lower temperature in the surface layers of the tool.

Cutting regimes - The cutting forces disproportionally decrease with an increase in the cutting speed (Tanikić et al., 2009a). For example, increasing in cutting speed by approximately $500 \%$ causes decreasing in the cutting force of about $21 \%$ (O'sullivan \& Cotterell, 2001). The amount of the heat generated during the metal cutting process depends on both factors: the cutting speed and the cutting force. Generally, the higher temperature is generated with increasing the cutting speed. The cutting force, as stated previously, increases disproportionally with an increase in the feed rate and therefore the cutting temperature increases, too. Increase of the cutting force and the cutting temperature is slower than the feed rate increase. Results of many experiments show that the cutting temperature depends on a large number of factors, which can be expressed by the following equation (Radovanović, 2002):

$$
T=C_{T} a^{k_{a T}} f^{k_{f T}} v^{k_{v T}}
$$

where: $T[\mathrm{~K}]$ - cutting temperature, $a[\mathrm{~mm}]$ - depth of cut, $f[\mathrm{~mm} / \mathrm{rev}]$ - feed rate, $v[\mathrm{~m} / \mathrm{min}]$ cutting speed, $C_{T}$ - general coefficient, $k_{a T}, k_{f T}, k_{v T}$ - exponents

General coefficient $C_{T}$ and exponents: $k_{a T}, k_{f T}, k_{v T}$ depend on the workpiece and the tool material characteristics, tool geometry, type of coolant etc...

Tool geometry - Cutting temperature directly depends on the cutting tool angles as well as the nose radius. The cutting tool angles define the size and the position of the maximum heated area. The larger the nose radius, the greater the resistance force and the cutting temperature. Increasing the nose radius also has a positive effect, such as increasing the active cutting edge, i.e. the area which is in the focus of deformation. In that way, better heat conduction through the tool and the workpiece is provided.

Type of coolant - Using the coolant fluids the temperature is reduced in two ways. Firstly, an amount of generated heat is carried away directly with the cutting fluid. The second one is the positive influence on the lubrication and the reduction of the friction between the tool and the workpiece. The coolant fluid jet must be directed to the contact point of the tool and the workpiece, while the quantity of the used fluid depends on the cutting speed. 


\subsection{Methods for temperature measuring in metal cutting process}

A large number of temperature measurement methods in the metal cutting have been developed in the past years. This section gives a brief history of these methods.

Thermocouples - Thermocouples are frequently used transducers in temperature measuring because they are rugged, they cover a wide temperature range and they are relatively inexpensive (O'sullivan \& Cotterell, 2001). When two dissimilar metals touch each other, the contact point produces a small open circuit voltage, which is proportional to the temperature difference of the connected metals. If these two metals are the tool and the workpiece, this thermocouple is then called a "tool-work thermocouple", or "toolchip" thermocouple. These kind of thermocouples are used for temperature measurements in the contact area of the tool and the chip. The cutting zone forms, so called, a "hot junction", which produces thermo-electric emf (electro magnetic force), while the cutting tool and/or the workpiece form, so called, a "cold junction". This technique is usually used for measuring the average temperature of the whole contact area. It is almost impossible to measure any brief variations of temperature with this method. An error occurs in temperature measurement when a BUE is formed during the cutting process. A drawback of this method is the fact that a coolant fluid cannot be used during the measurement. The cutting tool and the workpiece must be built from an electro conductible material and the system calibration is necessary on every single setup. The constraint of this method is also in the type of workpiece material, which can't be made from an easily melted material.

Inserted thermocouples - In order to improve the performance of the earlier mentioned system, thermocouples are inserted into the cutting tools in a special way which allows them to measure the temperature in a single or several points at the same time (Childs et al., 2000). The negative side of this method is that it requires drilling a few holes in the tool or in the workpiece, where the thermocouples are nested, very closely to the place where temperature is measured, in order to ensure accuracy. This method was used for measuring cutting temperatures in cutting steels, and cutting various alloys, on the lathes and on the milling machines (Kitagawa et al., 1997).

Radiation methods - This category includes methods for measuring temperature at a single point, or measuring temperature field, without the direct contact between the measuring instrument and the object. In the single point temperature measurements an infrared pyrometer is used, while in the measuring temperature field (infrared thermograph) specially made infrared cameras sensitive to radiation of the body which is heated are used (Abukhshim et al., 2006). Radiation methods have a large number of conveniences with respect to conduction methods. The most important are: faster response of the system, i.e. possibility of measuring brief variations of the temperature, there is no negative influence on the tool and the work material, there is no physical contact between the measuring system and the object, remote temperature measuring for 
inaccessible objects etc... During temperature measurement process using the infrared camera, there is a possibility that unwanted hiding of the measuring point with the chip may happen, which implies obtaining faulty data (Young, 1996). The other negative side of this method of temperature measurement is the fact that it requires knowledge of the exact value of the coefficient of emission for precise measuring. In order to overcome this problem, the area of interest can be painted with the paint with known coefficient of emission. Coefficient of emission depends on the clarity of the target area, presence of the oxidation covering, the wave length etc. Any of the above mentioned factors have an influence on the distraction of measured data.

Metallographic techniques - This method involves analysis of microstructure and/or micro hardness of the heat affected zones. It requires calibration curves which show the level of dependence of the material hardness in terms of the known temperatures and the time of heating. The usual accuracy of this method is $\pm 25^{\circ}$ (Wright, 1978). These methods are mainly used for temperature measurements of the cutting tools made from high speed steels, because they show structural changes, and/or hardness, in the temperature range of 600$1000^{\circ} \mathrm{C}$.

Other methods - These methods include methods for temperature measurement using thermo-sensitive paints, liquid crystals, fine powders etc. and are mainly limited to measurement of the visible areas in the special laboratory conditions (Ay \& Yang, 1998).

Generally, there are no strictly defined rules to determine which method is the most adequate one in a given situation. On the other hand, high complexity of the process itself does not always permit to compare results obtained by different methods. The best illustration of the above mentioned is the fact that even the results obtained by the same method in completely identical experiment conditions can be different, which is another proof of complexity of temperature measurement in the metal cutting process.

\section{Experimental research}

The lathe, which was used for examining and measuring, is located in the Laboratory for Production Engineering, at the Mechanical Engineering Faculty in Niš, Serbia. The workpiece material used is steel, with AISI designation 4140. This steel belongs to the group of doped, decent, cold drown steels, with strength of $R_{m}=1050$ [N/mm²]. Four thermally treated metal specimens, with measured hardness of HRC 20, 36, 43 and 55, were machined. The dimensions of the workpieces are $\phi 45 \times 250[\mathrm{~mm}]$.

Fig. 3. shows the component relations and information flow of the material handling system, and linked information system, which processes the obtained data.

SANDVIK Coromant cutting tool has been chosen, which consists of two parts: tool holder PCLNR 3225 P12 in combination with cutting insert CNMG 120408 (grade 235), according to the recommendations of the manufacturer and the empirical knowledge. 


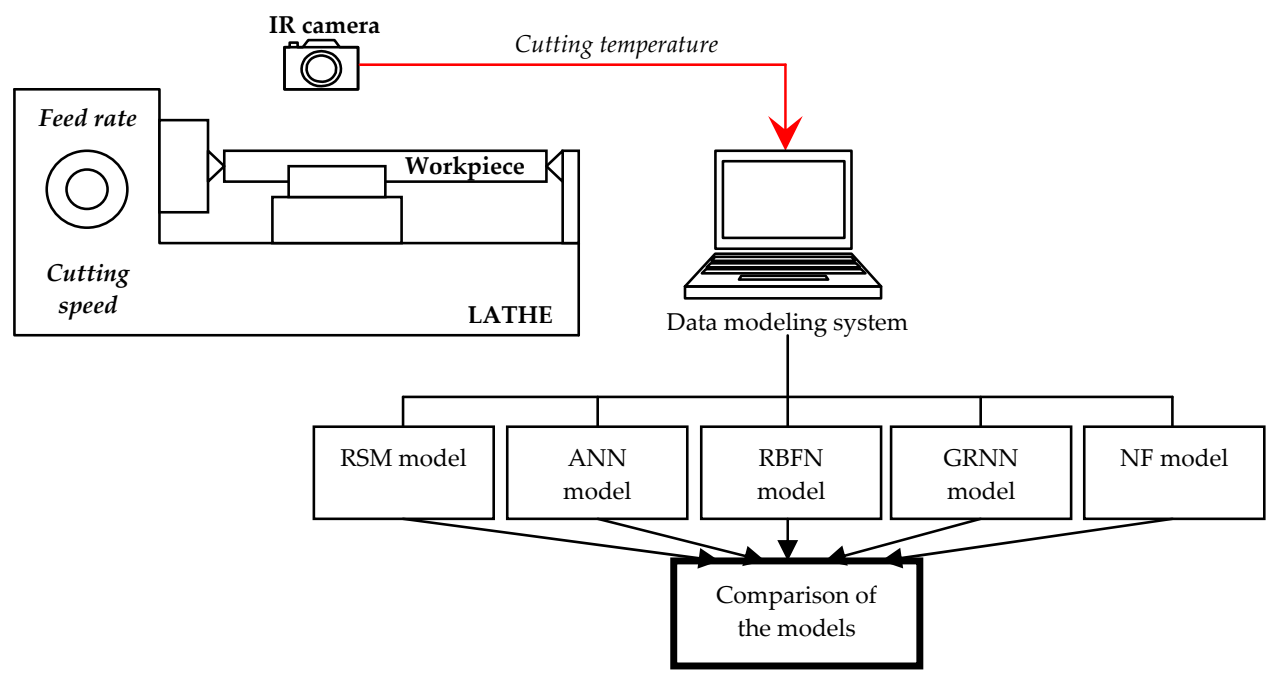

Figure 3. Schematic representation of the information flow in the system

Jenoptik Varioscan 3021-ST infrared camera has been used for temperature measurement. Varioscan high resolution is scanning thermovisics measured system, for wave lengths outside of the vision spectrum, from $8 \mu \mathrm{m}$ to $12 \mu \mathrm{m}$, i. e. in the area of infrared emission. Signal from this spectrum is amplified, digitalized with 16 bites and visualized. Every color on the shown thermagram (Fig. 4.) represents particular temperature. Temperature resolution of this system is $0.03^{\circ} \mathrm{C}$, while operating range of the camera is $-40^{\circ} \mathrm{C}$ to $+1200^{\circ} \mathrm{C}$.
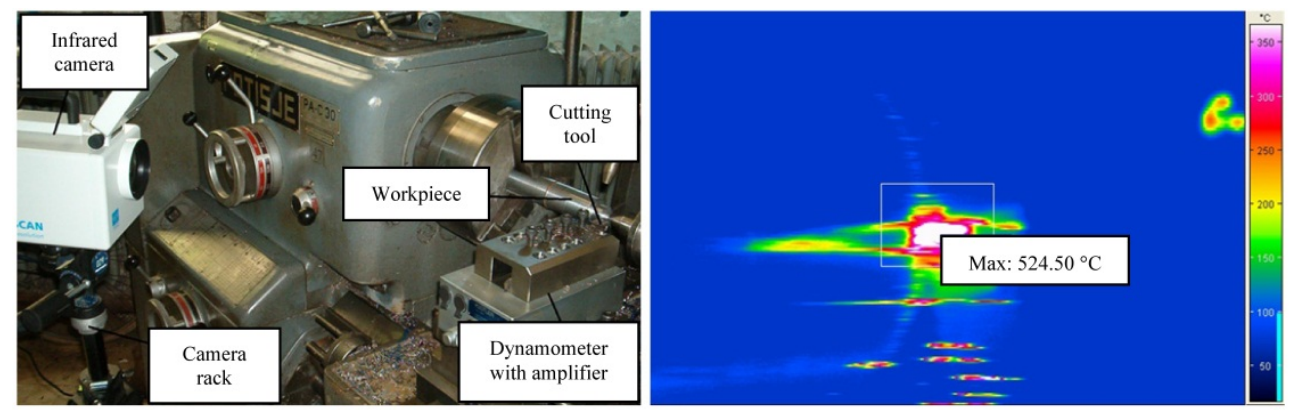

Figure 4. Experiment setup and thermagram $(v=125[\mathrm{~m} / \mathrm{min}], f=0.196[\mathrm{~mm} / \mathrm{rev}]$ and $t=2[\mathrm{~mm}])$

The most important temperature, from the metal cutting process point of view, is maximum temperature of the cutting tool. This temperature directly affects cutting characteristics of the tool, tool and workpiece deformation as well as the quality of the machined surface. It is 
obvious that measuring of the rake face of the cutting insert, where maximum temperature occurs, is not possible using mentioned infrared camera, because of continual presence of the chip which covers the area of interest. With known values of chip's top temperature, cutting depth and physical properties of the workpiece it is possible (using, for example, finite-difference model or FEM analyses) to calculate maximum cutting tool temperature. However, the primary goal of this work is exploring the possibility of using the means of artificial intelligence in modelling cutting temperature (and not measuring the exact value of maximum cutting temperature), and that's the reason why chip's top temperature is adopted as relevant parameter.

In the beginning of the metal cutting process temperature rises, until it reaches the maximum value. That's the reason why the measurement should be performed a small period of time after the beginning of the process (Kwon et al., 2001). After observing rise in the temperature and its distribution at the beginning of the process with an infrared camera, it is concluded that a period of about 60 seconds is enough for stabilizing the measured temperature. The pictures (Fig. 4.) are submitted to a PC memory card, and later analysed. The maximum cutting temperature which occurs on the chip's top is used for temperature modelling in the next phase of this work.

\subsection{Measured results and discussion}

Modelling of the chip's top temperature requires a large number of experiments with different cutting regimes. As mentioned, in addition to the recommended data obtained from the appropriate literature, the empirical knowledge is of crucial importance in making a proper choice of cutting regimes. The adopted variable process parameters are:

$\begin{array}{lll}\text { - } & \text { Material's hardness } & \text { HRC } \\ \text { - } & \text { Cutting speed } & v[\mathrm{~m} / \mathrm{min}] \\ \text { - } & \text { Feed rate } & f[\mathrm{~mm} / \mathrm{rev}] \\ \text { - } & \text { Depth of cut } & t[\mathrm{~mm}]\end{array}$

(values: HRC 20; 36; 43 and 55) (values: $80 ; 95 ; 110 ; 125$ and $140[\mathrm{~m} / \mathrm{min}]$ ) (values: $0.071 ; 0.098 ; 0.196$ and $0.321[\mathrm{~mm} / \mathrm{rev}]$ ) (values: $0.5 ; 1 ; 1.5$ and $2[\mathrm{~mm}]$ )

Results of the temperature measurement are given in Fig. 5.a. to 5.d. From the presented figures, it can be concluded that, with increasing the cutting speed (while other parameters remain constant) the resistance force of the cutting increases too, resulting in the increase in the chip temperature. It is also obvious that larger values of temperature occur in machining of the hardened workpiece materials. The chip temperature increases with increasing the depth of cut, too (with constant values of feed rate and cutting speed). The feed rate also has influence on changes in the cutting temperature, which is particularly apparent at low cutting speeds.

The irregularities in the following figures (the peaks in the diagrams of the chip's top temperature) can be interpreted as measuring errors. Anyway, the correlations among cutting regimes and corresponding temperature (trendlines of chip's top temperature) can be achieved. 

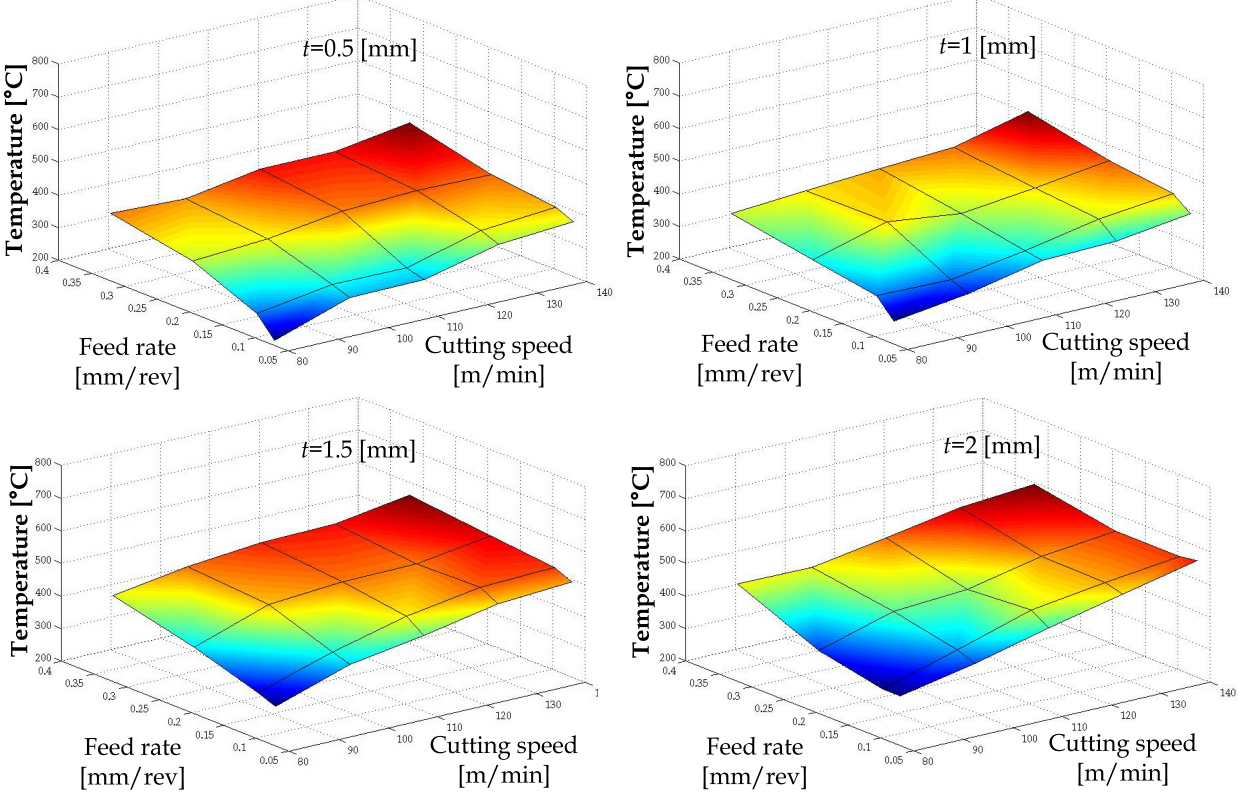

(a)
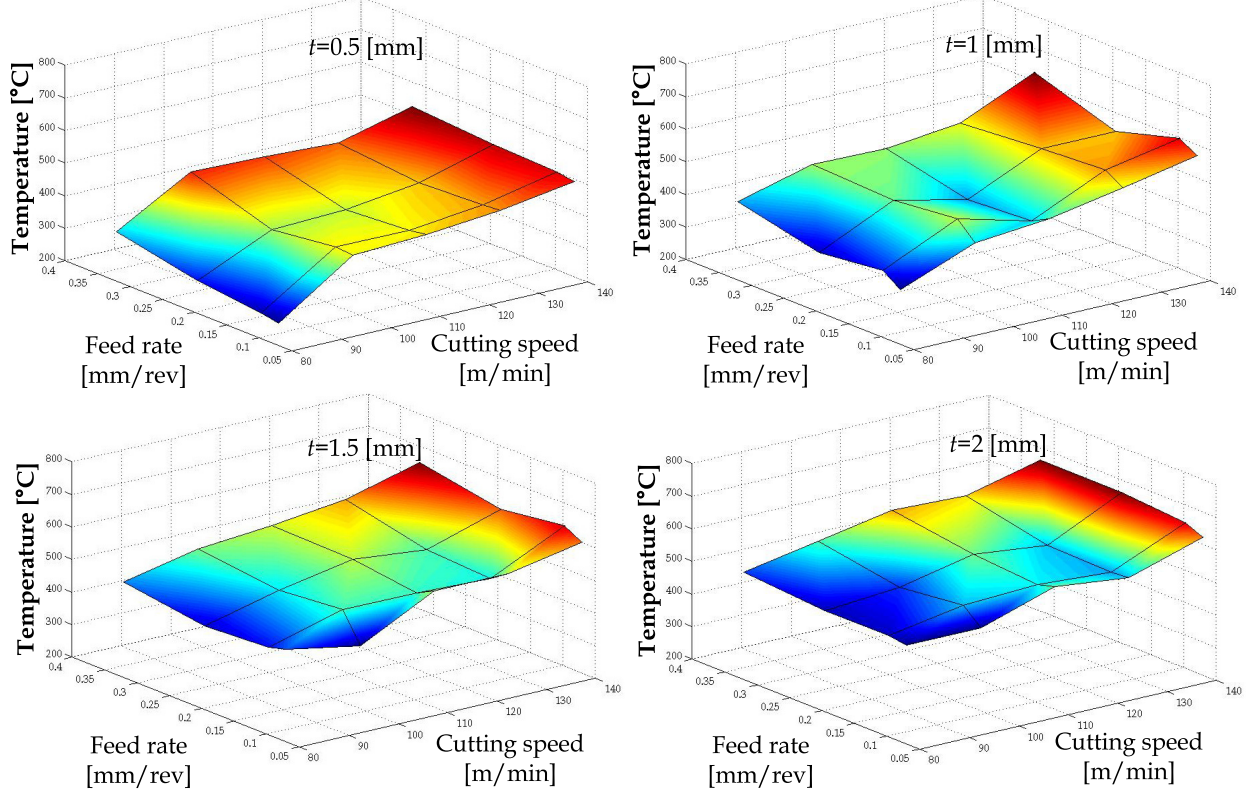

(b) 

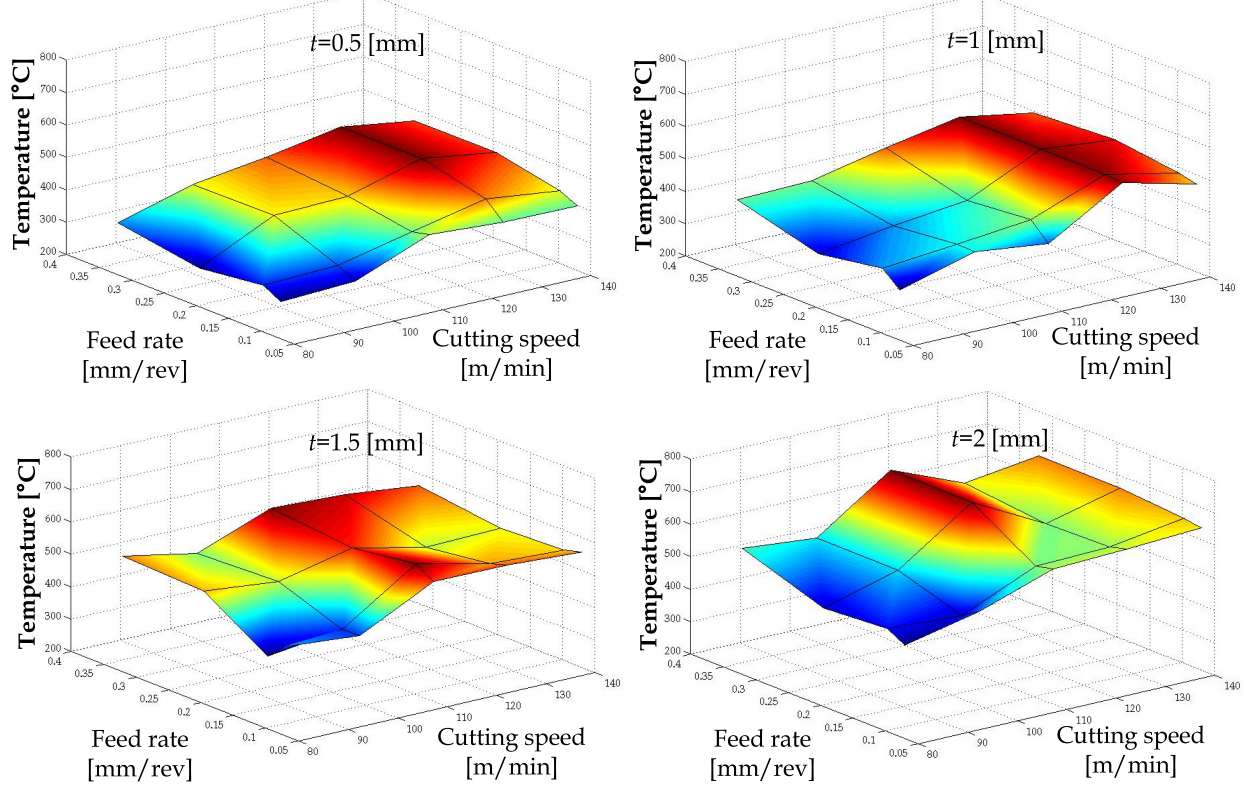

(c)
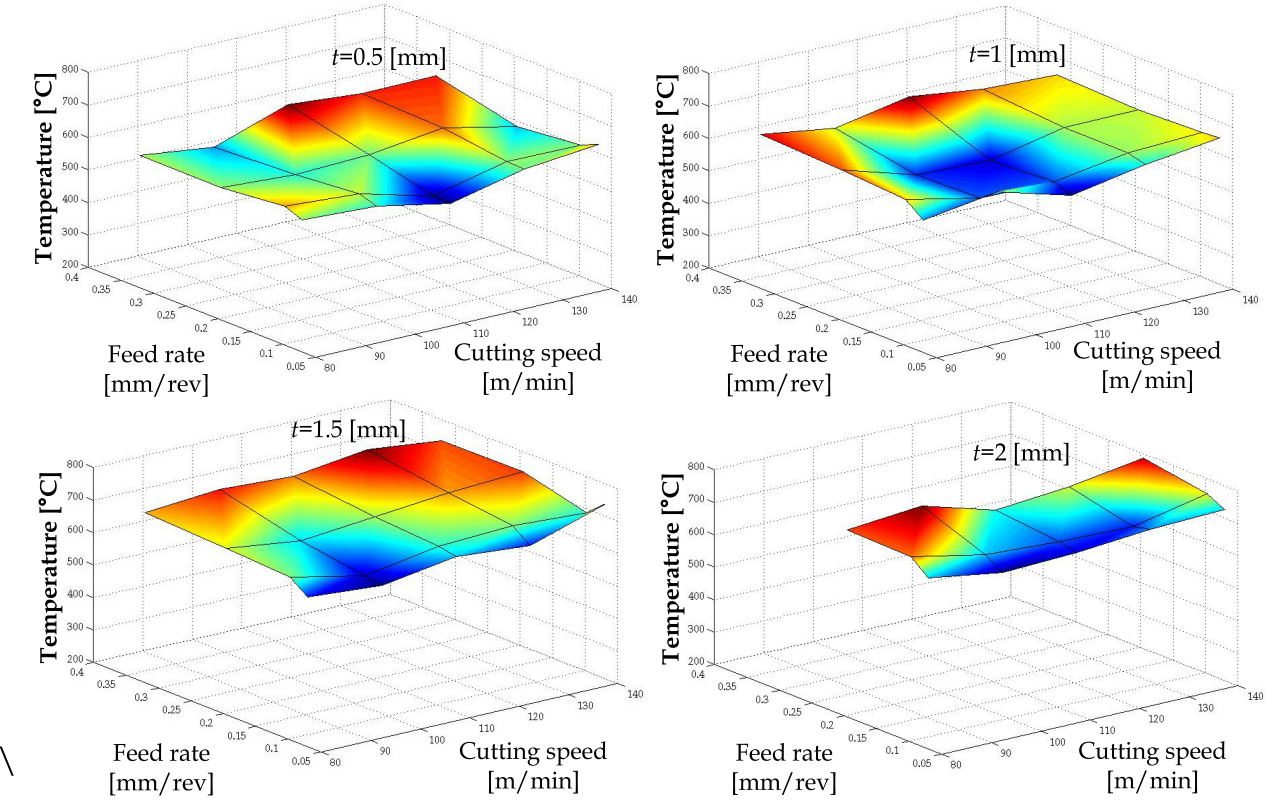

(d)

Figure 5. a) Chip temperature variation for the workpiece with hardness HRC 20; b) Chip temperature variation for the workpiece with hardness HRC 36; c) Chip temperature variation for the workpiece with hardness HRC 43; d) Chip temperature variation for the workpiece with hardness HRC 55 
Overall number of experiments carried out is 316, and obtained values can be used for modelling and simulation using various methodologies and FEM analysis. In recent years the research is directed on the use of systems based on artificial intelligence: artificial neural networks, fuzzy logic systems, genetic algorithms, as well as combination of mentioned systems (Tanikić \& Marinković, 2011, 2012), (Manić et al., 2005, 2011), (Devedžić et al., 2010), (Tanikić et al., 2008, 2009b).

\section{Modelling of the cutting temperature}

In this section, results obtained in the first phase are used for modelling of the cutting temperature using response surface methodology, feed forward artificial neural networks, radial basis function network, generalized regression neural network and adaptive neurofuzzy system. A comparative study of proposed models is given, and testing of the models was performed on the set of measured data which was not used in the modelling phase.

\subsection{Modelling using Response Surface Methodology (RSM model)}

Response Surface Methodology (RSM) is a tool for understanding the quantitative relationship between multiple input variables and one output variable. It is the process of adjusting predictor variables to move the response in a desired direction and, iteratively, to an optimum. RSM model is formulated as following polynomial function (Erzurumlu \& Oktem, 2007):

$$
f=a_{0}+\sum_{i=1}^{n} a_{i} x_{i}+\sum_{i=1}^{n} \sum_{j=1}^{n} a_{i j} x_{i} x_{j}+\ldots+\varepsilon \quad i<j
$$

where: $a_{0}, a_{i}, a_{i j} \ldots$ - tuning parameters, $n$ - number of model parameters

Four different models are created from the set of 316 measured data. First model uses only constant and linear terms (Linear model), second model uses constant, linear and squared terms (Pure quadratic model), third model uses constant, linear and cross product terms (Interactions model) and fourth model uses constant, linear, squared and cross product terms (Full quadratic model). The coefficients of the proposed models are shown in Table 1. This method is simpler than standard nonlinear techniques for determining optimal designs.

The set of 122 measured data (testing set), which was not used in the modelling phase was used for models testing. Some of the calculated temperatures with different RSM models are shown in Fig. 6. (32 data sets obtained during machining workpiece with hardness HRC 20). The conclusion is that Full quadratic model has the best characteristics (the least values of maximum as well as mean error), and that model will be compared with the other models, which will be created in the next sections. 


\begin{tabular}{|c|c|c|c|c|c|c|c|c|c|c|c|c|c|c|c|}
\hline Model & const. & $H$ & $v$ & $f$ & $t$ & $H \times v$ & $H \times f$ & $H x t$ & $v \times f$ & $v \times t$ & $f x t$ & $H^{2}$ & $v^{2}$ & $f^{2}$ & $t^{2}$ \\
\hline Linear & -74.33 & 6.472 & 1.671 & 227.7 & 102.0 & & & & & & & & & & \\
\hline $\begin{array}{c}\text { Pure } \\
\text { quadratic }\end{array}$ & 69.13 & -7.825 & 3.248 & 252.1 & 109.7 & & & & & & & 0.193 & -0.007 & -45.53 & -2.692 \\
\hline Interactions & -344.7 & 12.60 & 3.860 & 742.1 & 83.73 & -0.050 & -6.597 & 0.396 & -2.076 & 0.067 & -26.65 & & & & \\
\hline $\begin{array}{c}\text { Full } \\
\text { quadratic }\end{array}$ & -190.0 & -1.888 & 5.416 & 727.9 & 85.90 & -0.051 & -5.806 & 0.519 & -2.199 & 0.048 & -8.203 & 0.193 & -0.007 & -46.12 & -2.711 \\
\hline
\end{tabular}

Table 1. The coefficients of the proposed RSM models

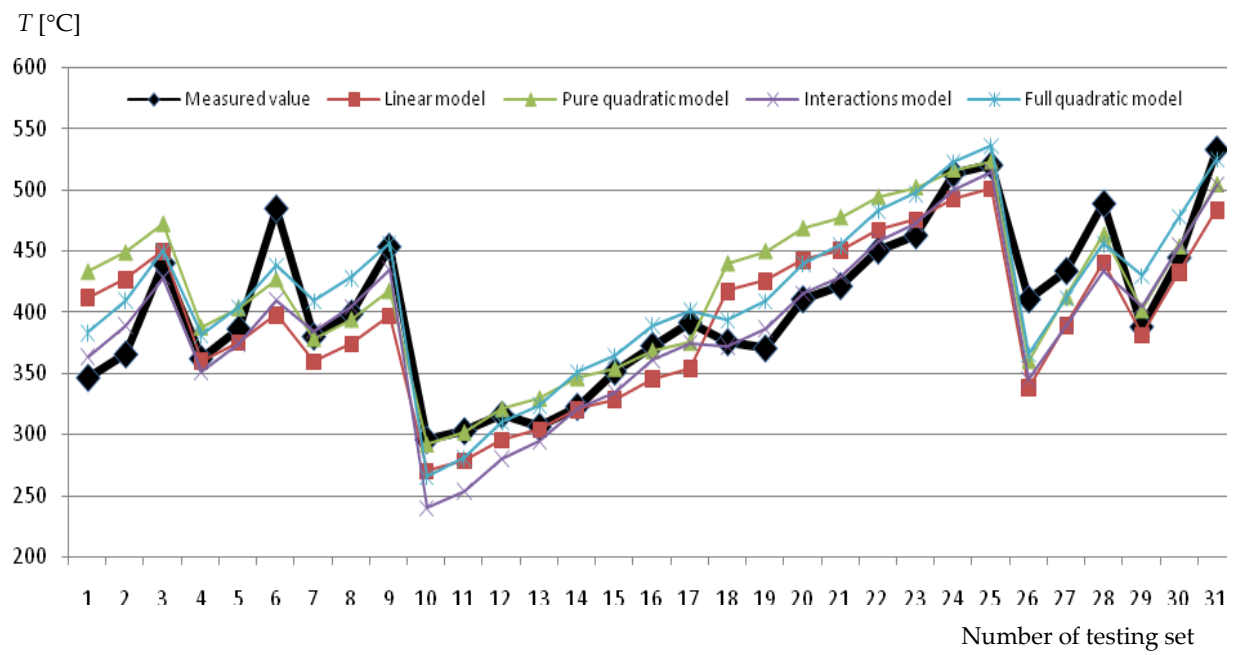

Figure 6. Predicted temperatures with different RSM models

The maximum and mean errors of the proposed models are presented in Table 2.

\begin{tabular}{|c|c|c|c|c|}
\hline & Linear model & $\begin{array}{c}\text { Pure quadratic } \\
\text { model }\end{array}$ & $\begin{array}{c}\text { Interactions } \\
\text { model }\end{array}$ & $\begin{array}{c}\text { Full quadratic } \\
\text { model }\end{array}$ \\
\hline $\begin{array}{c}\text { Max. error } \\
{[\%]}\end{array}$ & 23.555 & 25.247 & 25.078 & 18.343 \\
\hline $\begin{array}{c}\text { Mean error } \\
{[\%]}\end{array}$ & 8.193 & 7.218 & 7.609 & 6.901 \\
\hline
\end{tabular}

Table 2. The errors of the different RSM models 


\subsection{Modelling using Artificial Neural Networks (ANN model)}

Artificial Neural Network (ANN) is a structure which is able to receive input vector $I=\left[i_{1}, i_{2}\right.$, $\left.\ldots, i_{n}\right]$, and generate appropriate output vector $O=\left[o_{1}, o_{2}, \ldots, o_{m}\right]$ (Santochi \& Dini, 1996). The ANN contains several connected elementary calculation units, which are called neurons. Fig. 7. shows a schematic representation of an artificial neuron with input vector (with $r$ elements) and characteristic structure of the feed forward ANN with $k$ hidden layers.

Each of the input elements $x_{1}, x_{2}, \ldots, x_{r}$ is multiplied with the corresponding weight of the connection $w_{i, 1}, w_{i, 2}, \ldots, w_{i, r}$. The neuron sums these values and adds a bias $b_{i}$ (which is not present in all networks). The argument of the function (which is called transfer function) is given as follows:

$$
a_{i}=x_{1} w_{i, 1}+x_{2} w_{i, 2}+\ldots+x_{r} w_{i, r}+b_{i}
$$

while neuron produces output:

$$
y_{i}=f\left(a_{i}\right)=f\left(\sum_{j=1}^{r} x_{j} w_{i, j}+b_{i}\right)
$$

This output represents an input to the neurons of another layer, or an element of the output vector of the ANN.

In this particular case, input layer of all created ANNs has four neurons: (1) Material hardness, (2) Cutting speed, (3) Feed rate and (4) Depth of cut, and only one output neuron for predicting chip's top temperature.

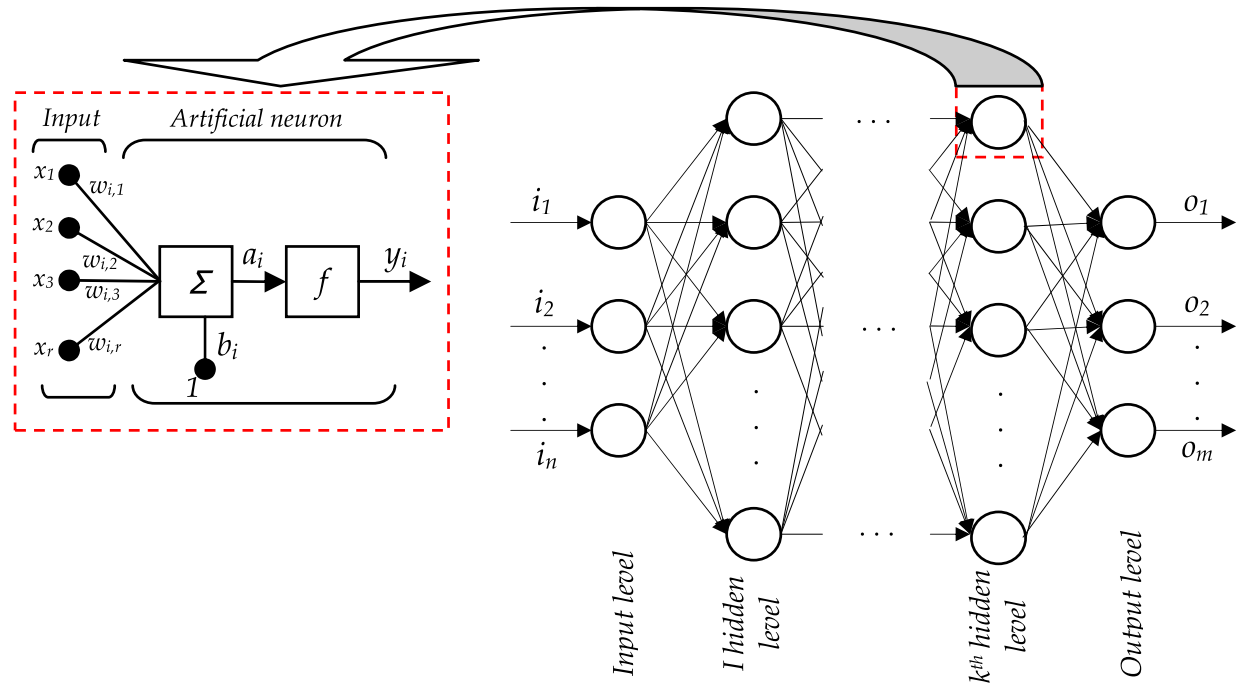

Figure 7. Artificial neuron and the structure of the feed forward artificial neural network 
The artificial neural networks, as known, can have random number of layers and random number of neurons in them. Performance of ANN depends on the number of layers, number of neurons, transfer function, presence of a bias as well as on the way the neurons are connected. Unfortunately, there are no formal rules for proper choice of mentioned parameters. In principle, determining all of these parameters is done using personal skills and experience. In the present work six different neural networks with different number of layers and neurons are created in order to achieve minimum error on the one side and avoid overfitting (the situation when the network has a low capability of generalization) on the other side. The structure of the proposed networks are: ANN 4-3-1 (one hidden layer with 3 neurons); ANN 4-5-1 (one hidden layer with 5 neurons); ANN 4-10-1 (one hidden layer with 10 neurons); ANN 4-2-2-1 (two hidden layers with 2 neurons in each layer); ANN 4-5-3-1 (two hidden layers with 5 and 3 neurons, respectively) and ANN 4-10-5-1 (two hidden layers with 10 and 5 neurons, respectively). The main goal is to minimize the performance function, in this case mean squared error (mse) function, which can be calculated as:

$$
m s e=\frac{1}{Q} \sum_{k=1}^{Q} e(k)^{2}=\frac{1}{Q} \sum_{k=1}^{Q}(t(k)-y(k))^{2}
$$

where: $Q$ - number of experiments, $e(k)$ - error, $t(k)$ - target values, $y(k)$ - predicted values

The training algorithm used in all cases is Levenberg-Marquardt algorithm which provides the best convergence in the cases of approximation of an unknown function (function prediction), and the number of training cycles is 500. The neurons in input and hidden layers of ANNs have sigmoid transfer function, while the neurons of the output layer have linear transfer function. Minimization of the mse, depending on number of training cycles, for various ANNs configurations is shown in Fig. 8.

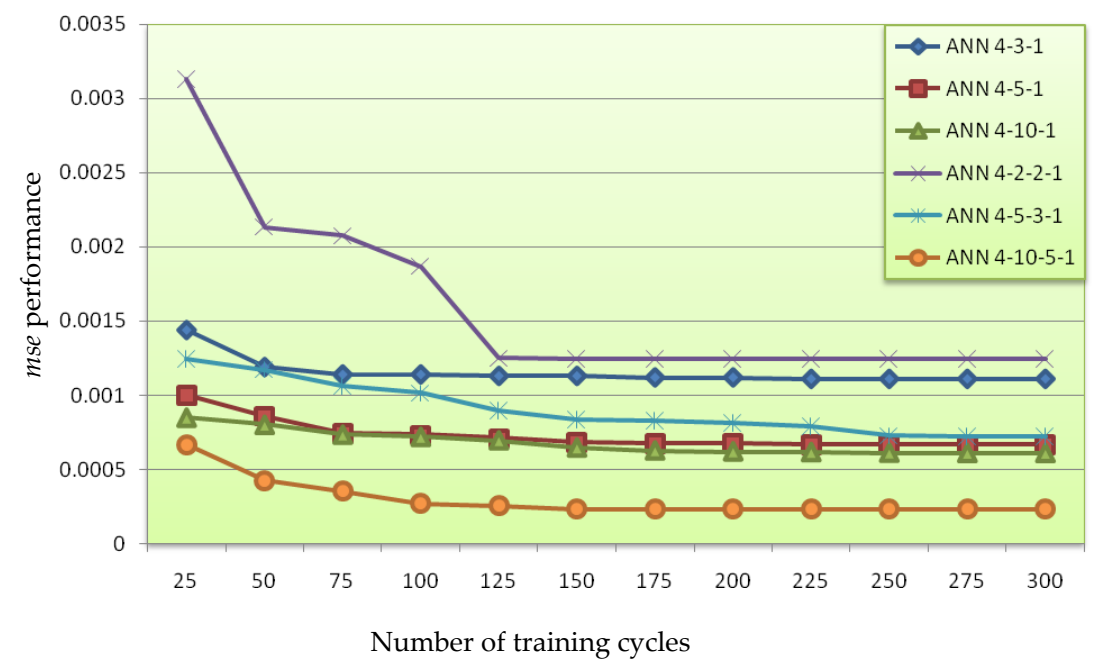

Figure 8. mse performance function depending on the number of training cycles 
After the training phase, the ANNs were tested. The set of 122 measured data (which was not used in the training phase) was used for testing the ANN models. Maximum and mean error of all proposed networks is given in Table 3.

\begin{tabular}{|c|c|c|c|c|c|c|}
\hline & ANN 4-3-1 & ANN 4-5-1 & ANN 4-10-1 & ANN 4-2-2-1 & ANN 4-5-3-1 & ANN 4-10-5-1 \\
\hline Max. error [\%] & 15.001 & 14.345 & 14.461 & 22.504 & 24.218 & 14.236 \\
\hline Mean error [\%] & 4.387 & 3.623 & 3.602 & 5.615 & 4.114 & 3.229 \\
\hline
\end{tabular}

Table 3. The errors of the different ANN models

The ANNs prediction, for the set of 32 measured data (obtained by measuring chip's top temperature while machining workpiece with hardness HRC 20) is shown in the Fig. 9. From given figure and table 3, it can be concluded that ANN 4-10-5-1 shows the best performance, and this network will be used for comparison with other models.

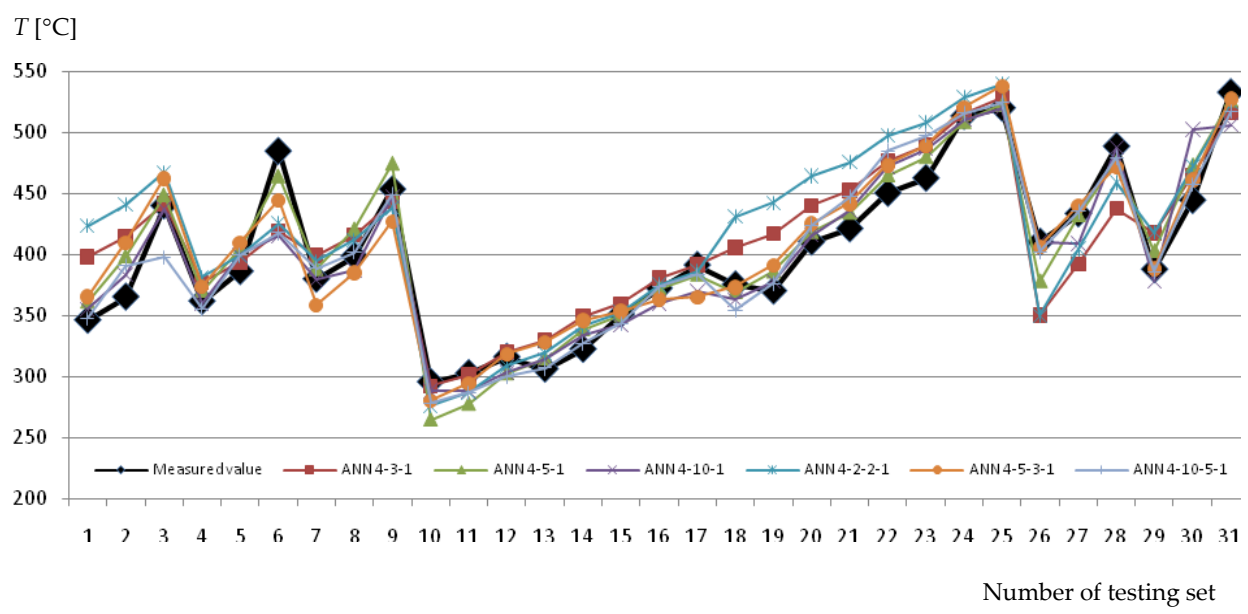

Figure 9. Predicted temperatures with different ANNs architectures

\subsection{Modelling using the Radial Basis Function Network (RBFN model)}

Radial basis function network (RBFN) employs local receptive fields to perform function mappings (Chen et al., 1991). Fig. 10. shows radial basis neuron and characteristic structure of RBFN. The output of the i-th receptive field unit (hidden unit) is expressed as:

$$
a_{i}=R_{i}(\vec{n})=R_{i}\left(\left\|\vec{x}-\vec{w}_{i}\right\| b\right), \quad i=1,2, \ldots, H
$$

where: $\vec{x}$ - input vector, $\vec{w}_{i}$ - weight vector (the same dimensions as $\vec{x}$ vector), $b$ - bias, $H$ - number of receptive field units, $R_{i}(\cdot)$ - i-th receptive field response with a single maximum at the origin 


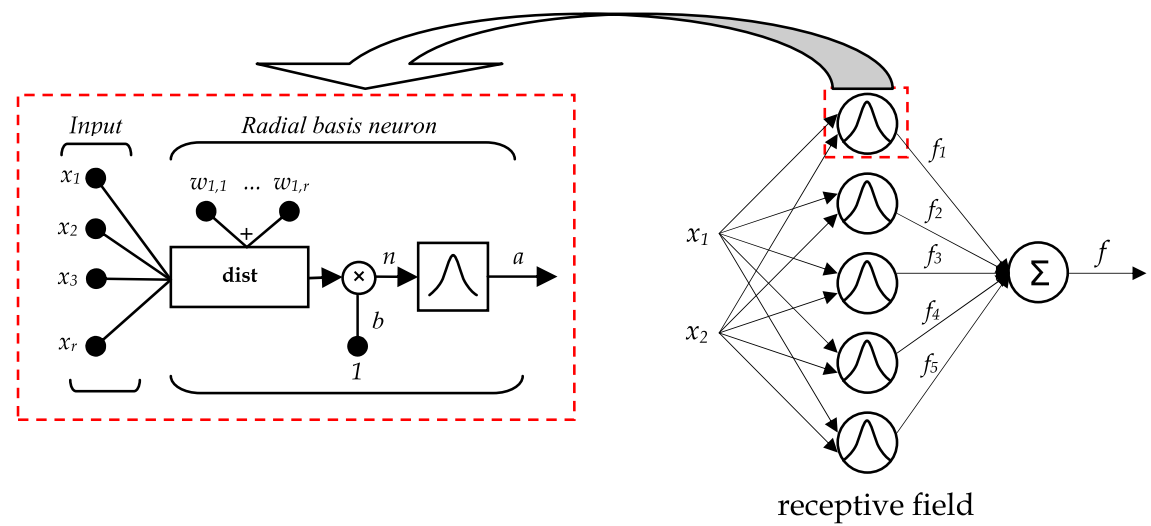

Figure 10. Radial basis neuron and characteristic structure of the radial basis function network

The transfer function for radial basis neuron has output 1 when its input is 0 . As the distance between $x$ and $w_{i}$ decreases, the output increases. The radial basis neurons with weight vectors quite different from the input vector $\vec{x}$ have outputs near zero and these small outputs have only a negligible effect on the overall output. In contrast, a radial basis neuron with a weight vector close to the input vector $\vec{x}$ produces a value near 1 . Typical transfer function of radial basis neuron is:

$$
R_{i}(\vec{n})=e^{-n^{2}}
$$

The output of the radial basis function network can be computed as follows:

$$
f(\vec{x})=\sum_{i=1}^{H} f_{i} a_{i}=\sum_{i=1}^{H} f_{i} R_{i}(\vec{n})
$$

In this case, set of 316 measured temperature data (and corresponding cutting regimes) was used for creating a radial basis function network, while the rest 122 data (testing set) was used for RBFN model testing. Maximum and mean errors of this model are $44.142 \%$ and $8.801 \%$ respectively. The prediction of the chip's top temperature of this model is given in the Fig. 11.

\subsection{Modelling using the Generalized Regression Neural Network (GRNN model)}

A General Regression Neural Network (GRNN) is a special type of neural network with radial basis function which is usually used for function approximation. It has two layers: radial basis layer (which is identical with radial basis layer in RBFN), and second, special linear layer (Wasserman, 1993). The number of neurons in radial basis layer is equal to the number of input/output data pairs. The argument of the radial basis function is a product of the weighed input (distance between the input vector and its weighted vector) and bias $b$. If a neuron's weight vector is equal to the input vector (transposed), its weighted input will be 0 , and its output will be 1 .The second layer also has same number of neurons as the number 
of input/output vectors. Given a sufficient number of hidden neurons, GRNNs can approximate a continuous function to an arbitrary accuracy. Generally, GRNN is slower to operate because it uses more computation than other kinds of networks to do their function approximation, but, taking in consideration the speed of the modern computers, this disadvantage became minor.

The same set of 316 training vectors was used for GRNN modelling, and testing was performed on the set of remaining 122 input/target vectors. The maximum error which GRNN produced is $16.907 \%$, while the mean error is $2.827 \%$. The graphic representation of the prediction of this network is given in the Fig. 11.

\subsection{Modelling using hybrid, Neuro-Fuzzy system (NF model)}

Adaptive Neuro-Fuzzy (NF) systems represent a specific combination of artificial neural networks and fuzzy logic, so they combine the ability of learning of artificial neural networks with the logical interpretation of fuzzy logic systems (Sick, 2002). The basic rule of the adaptive networks learning is based on a descent gradient method which was proposed in the 70s of the previous century (Werbos, 1974). Adaptive neuro-fuzzy network consists of many layers of nodes (neurons), each of which performs a particular function (node function) on incoming signals as well as a set of parameters pertaining to this node. The type of the function which the node performs may vary from node to node, and the choice of node function depends on overall input-output function that network simulates (Jang, 1993).

This system represents the way for adjusting existential base of rules, using the learning algorithm which is based on the assembly of input-output pairs, used for training. Taking into consideration some constraints, the architecture of the adaptive neuro-fuzzy system (ANFIS Adaptive-Network-based Fuzzy Inference System) is equivalent to radial basis function networks. The characteristic architecture of the adaptive neuro-fuzzy system is shown in Fig. 12.

For simplicity, suppose that system has only two input values $x$ and $y$ (Level 1), and one output value $z$ (Level 5). In the case shown in Fig. 12., the rule base consists just of two fuzzy IF-THEN rules (Takagi-Sugeno type), as shown in Level 2:

\section{Rule 1: IF $\underline{x \text { is } A_{1}}$ AND $y$ is $B_{1}$, THEN $f_{1}=p_{1} x+q_{1} y+r_{1}$ \\ Rule 2: IF $\underline{x \text { is } A_{2}}$ AND $y$ is $B_{2}$, THEN $f_{2}=p_{2} x+q_{2} y+r_{2}$}

First part of fuzzy rule (after the IF part of the rule) is called premise, while the second part of the rule (after the THEN part of the rule) is called consequent. From the ANFIS system architecture it is obvious that for the given values of premise parameters, the output value can be presented as linear combination of the consequent parameters. Mathematically, this can be presented as:

$$
\begin{aligned}
& f=\frac{w_{1}}{w_{1}+w_{2}} f_{1}+\frac{w_{2}}{w_{1}+w_{2}} f_{2}=\overline{w_{1}} f_{1}+\overline{w_{2}} f_{2}= \\
& =\left(\overline{w_{1}} x\right) p_{1}+\left(\overline{w_{1}} y\right) q_{1}+\left(\overline{w_{1}}\right) r_{1}+\left(\overline{w_{2}} x\right) p_{2}+\left(\overline{w_{2}} y\right) q_{2}+\left(\overline{w_{2}}\right) r_{2}
\end{aligned}
$$




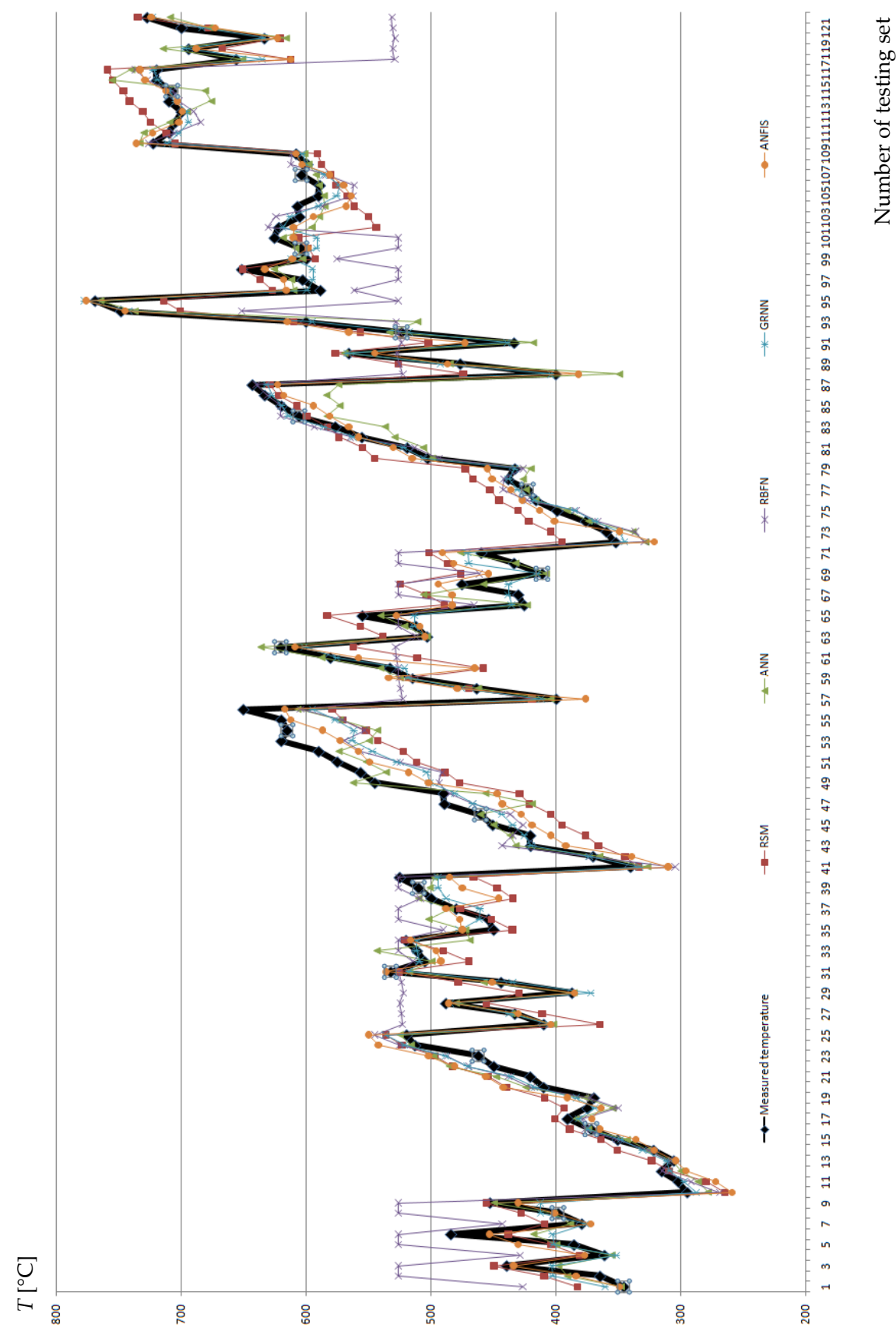

Figure 11. Measured and predicted temperatures with various models 


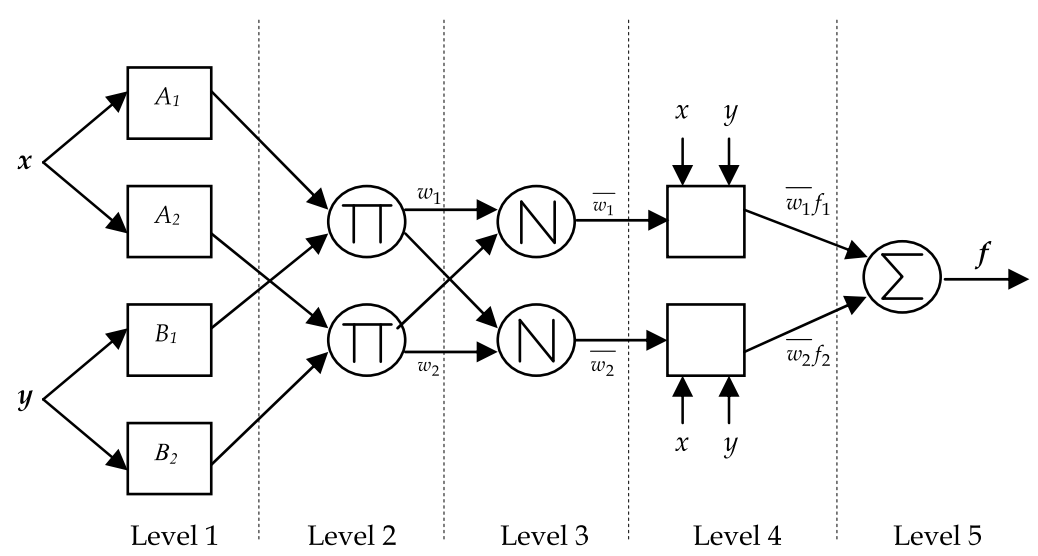

Figure 12. Characteristic structure of the neuro-fuzzy system

The adopted input and output parameters are the same as in other models. All the rules have unity weight, and all output membership functions are of the same type. The number of output membership functions is equal to the number of rules. After the extensive research of the various architectures of the NF systems, and their suitability for the proposed problem, the following parameters are adopted: the number of membership functions of each input is set to 3, the input membership functions are bell shaped, the hybrid optimization method is used, and number of training epochs is 300. A set of 316 measured data is used for training and the rest 122 data sets are used for model testing.

After the successfully finished learning phase, the neuro-fuzzy system accomplished data generalization, and in the modelled field, the value of the chip's top temperature can be predicted without any measurement.
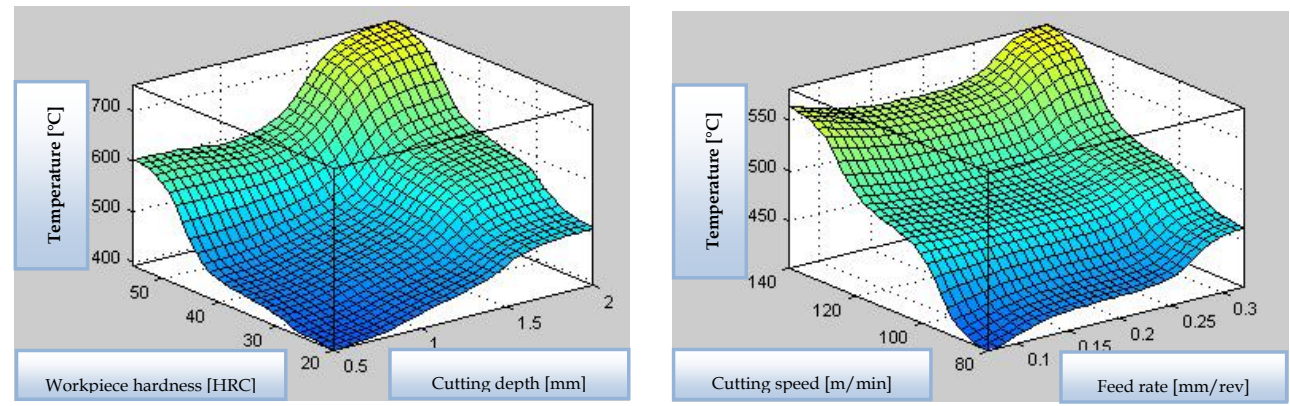

Figure 13. Chip's top temperature depending on two input variables

Graphical representation of the predicted temperature depending on two input variables is shown in Fig. 13 (the input variables combination is arbitrarily). Maximum error achieved in the model testing is $13.439 \%$, while the mean error is $4.319 \%$. The results of the tentative work of the NF system is shown in Fig. 11. 


\section{Results and comparison of the proposed models}

This section presents a comparative study of the proposed models. Testing set of 122 input/target (measured) vectors, not used in the modelling phase was used for checking the accuracy of created models.

The percentage error is defined as follows:

$$
e(k)[\%]=\left|\frac{t(k)-y(k)}{t(k)}\right| \times 100
$$

where: $e(k)$ - error of the $k$-th experiment, $t(k)$ - measured value of the $k$-th experiment and $y(k)$ - predicted value of the $k$-th experiment

Maximum and mean errors can be calculated as follows:

$$
\begin{gathered}
\text { Max. error }[\%]=\max e(k), k=1,2, \ldots, n \\
\text { Mean error }[\%]=\frac{\sum_{k=1}^{n} e(k)}{n}
\end{gathered}
$$

where: $n$ - total number of experiments

Response Surface Methodology includes experimental investigations, mathematical methods and statistical analysis.

The advantage of this methodology is in the fact that parameters of the RSM model have meaning, i.e. the coefficient which multiplies some input variable provides some information regarding the influence of that variable on the output value, which is not the case when using the artificial intelligence based models.

The disadvantage of this methodology is the fact that they can be very complex, demanding significant time for data gathering, calculation of all the relevant factors and parameters, and analyzing their influence on the objective.

Artificial neural networks may be considered as parametric functions, and their training involves parameter estimation or fitting process.

The main advantage of the ANNs is that there is no need to explicitly formulate the problem, the solution algorithm, or to be familiar with computer programming. They can also manage noisy or incomplete data, as well as experimentally obtained data, with very complex (or unknown) representation, like in the case presented in this chapter.

The drawback of this methodology is the lack of the principles for determining the optimal network architecture, i.e. the number of layers and the number of neurons in them, as well as the type of their transfer functions. This process can be very complex and time consuming. The principle used in this work implies starting with the minimum number of 
layers and neurons, creating and training the ANN (tracing the convergence and error), and testing it at the end. After that, the number of neurons and/or layers is raised, and the whole procedure is repeated until the test results became acceptable. As it can be seen, the whole process is highly individual. Finally, the serious drawback of the ANNs is that the resulting performance of the adopted model in an application can't be guaranteed.

Radial basis function networks are successfully used in prediction problems, especially when large number of input variables are present and corresponding output vectors are available, which was exactly the case in our study.

The disadvantage of this model is that they need more neurons and slightly more computational time than standard feed-forward backpropagation networks. Considering the overall operating time of proposed models, this disadvantage becomes irrelevant.

Generalized regression neural network is a special type of RBFN, specialized for function prediction. It can be concluded that maximum and minimum values of Mean errors were obtained using RBFN and GRNN models, respectively. Both networks have the same first, radial basis layer. However, the second, special linear layer (which is present in GRNN model) obviously plays very important role, resulting in the best prediction capabilities among all of the presented models.

Neuro Fuzzy modelling provides a method for the fuzzy modelling procedure to learn information about a data set.

Some of the constraints of the ANFIS are that it must be first or zeroth order Sugeno-type system with a single output, obtained using weighted average defuzzification. Although this can be rectified, in this particular case it was irrelevant since only one output variable (chip temperature) was modelled.

Fig. 11 shows the measured and predicted values of all created models, while Table 4. shows their Maximum and Mean errors. Considering the Maximum error, it is obvious that Adaptive Neuro Fuzzy Inference System has the least value, while Generalized Regression Neural Network is the most accurate when considering the Mean error. The time needed for modelling is very similar for all models. The similar results were obtained when training and testing time were considered. The performances of the present computers make that differences negligible.

All of the proposed models, except RSM model, are black boxes, i.e. the influence of any input variable on the objective is unknown at all, and this fact is one of the main drawbacks of many artificial intelligence techniques.

\begin{tabular}{|c|c|c|c|c|c|}
\hline & RSM & ANN & RBFN & GRNN & ANFIS \\
\hline Max. error [\%] & 18.343 & 14.236 & 44.142 & 16.907 & 13.439 \\
\hline Mean error [\%] & 6.901 & 3.229 & 8.801 & 2.827 & 4.319 \\
\hline
\end{tabular}

Table 4. Maximum and mean errors of the created models 
The methodologies that are presented in this chapter demonstrate both advantages and disadvantages when compared to each other. The most suitable model for the task under consideration seems to be the Generalized Regression Neural Network and Adaptive Neuro Fuzzy Inference System.

\section{Conclusion}

The primary goal of this work is examination the possibility of using various models (most of them based on artificial intelligence) in metal cutting temperature modelling. The maximum chip's top temperature was adopted as relevant factor. The infrared method, used in this work, gives a relatively good indication of the measured temperature.

Relationships among the input and corresponding output variables are established from the measured data, as well as trends of temperature changing with cutting regimes and material property changes. Furthermore, modelling of the measured data was performed using the response surface methodology, various types of artificial neural networks and hybrid, neuro-fuzzy system. Almost all of the proposed models can be used for temperature prediction with relatively good accuracy.

Proper selection of the cutting tool, main and auxiliary equipment as well as cutting regimes is of the crucial importance in metal cutting process. Modelling of the main process indicators (such as cutting temperature) can be very useful, and it can help machine shops to machine under optimum conditions, and in that way to reduce the production costs, which is the main goal of any manufacturing production.

\section{Author details}

Dejan Tanikić \& Vladimir Despotović

University of Belgade, Technical Faculty in Bor, Serbia

\section{Acknowledgment}

Research work presented in the paper is funded by the Serbian Ministry of Science within the projects TR34005 and III41017.

\section{References}

Abukhshim, N.A., Mativenga, P.T. \& Sheikh, M.A. (2006). Heat generation and temperature prediction in metal cutting: A review and implications for high speed machining. International Journal of Machine Tools \& Manufacture, Vol. 46, No. 7-8, pp. 782-800, ISSN 0890-6955

Arshinov, V. \& Alekseev, G. (1979). Metal cutting theory and cutting tool design, Mir Publishers, Moscow, USSR

Ay, H., Yang, W.-J. (1998). Heat transfer and life of metal cutting tools in turning. International Journal of Heat and Mass Transfer, Vol. 41, No. 3, pp. 613-623, ISSN 0017-9310 
Boud, F. (2007). Bar diameter as an influencing factor on temperature in turning. International Journal of Machine Tools \& Manufacture, Vol. 47, No. 2, pp. 223-228, ISSN 0890-6955

Chen, S., Cowan, C.F.N. \& Grant, P.M. (1991). Orthogonal Least Squares Learning Algorithm for Radial Basis Function Networks, IEEE Transactions on Neural Networks, Vol. 2, No. 2, pp. 302-309, ISSN 1045-9227

Childs, T., Maekawa, K., Obikava, T. \& Yamane, Y. (2000). Metal machining - theory and applications, Arnold, a member of the Hodder Headline Group, London, Great Britain

Devedžić, G., Manić, M., Tanikić, D., Ivanović, L. \& Mirić, N. (2010). Conceptual Framework for NPN Logic Based Decision Analysis, Strojniški vestnik - Journal of Mechanical Engineering, Vol. 56, No. 6, pp. 402-408, ISSN 0039-2480

Erzurumlu, T. \& Oktem, H. (2007). Comparison of response surface model with neural network in determining the surface quality of moulded parts. Materials and Design, Vol. 28, No. 2, pp. 459-465, ISSN 0261-3069

Jang, J.S.R. (1993). ANFIS: Adaptive-Network-Based Fuzzy Inference System. IEEE Transactions on Systems, Man and Cybernetics, Vol. 23, No. 3, pp. 665-685, ISSN 1083-4427

Kitagawa, T., Kubo, A. \& Maekawa, K. (1997). Temperature and wear of cutting tools in high speed machining of Inconel 718 and Ti-6Al-6V-2Sn. Wear, Vol. 202, No. 2, pp. 142148, ISSN 0043-1648

Kwon, P., Schiemann, T., Kountanya, R. (2001). An inverse scheme to measure steady-state tool-chip interface temperatures using an infrared camera. International Journal of Machine Tools \& Manufacture, Vol. 41, No. 7, pp. 1015-1030, ISSN 0890-6955

Manić, M., Tanikić, D. \& Nikolić V. (2005). Determination of the Cutting Forces in a Face Milling Operation Using the Artificial Neural Networks, Machine Dynamics Problems, Vol. 29, No. 3, pp. 51-59, ISSN 0239-7730

Manić, M., Tanikić, D., Stojković, M. \& Đenadić D. (2011). Modeling of the Process Parameters using Soft Computing Techniques, World Academy of Science, Engineering and Technology, Vol. 59, pp. 1761-1767, ISSN 2010-376X

Marinković, V., Tanikić, D. (2011). Prediction of the average surface roughness in dry turning of cold rolled alloy steel by artificial neural network, Facta Universitatis, Series: Mechanical Engineering, Vol. 9, No. 1, pp. 9-20, ISSN 0354-2025

O'sullivan, D. \& Cotterell, M. (2001). Temperature measurement in single point turning. Journal of Materials Processing Technology, Vol. 118, No. 1-3, pp. 301-308, ISSN 0924-0136

Radovanović, M. (2002). Tehnologija masinogradnje, obrada materijala rezanjem, Univerzitet u Nišu, Mašinski fakultet, Niš, Srbija (in serbian)

Santochi, M. \& Dini, G. (1996). Use of neural networks in automated selection of technological parameters of cutting tools. Computer Integrated Manufacturing Systems, Vol. 9, No. 3, pp. 137-148, ISSN 0951-5240

Sick, B. (2002). On-line and indirect tool wear monitoring in turning with artificial neural networks: a review of more then a decade of research. Mechanical Systems and Signal Processing, Vol. 16, No. 4, pp. 487-546, ISSN 0888-3270

Tanikić, D., Manić, M. \& Devedžić G. (2008). Chip's temperature modelling using the artificial intelligence methods, Tehnička dijagnostika/Technical Diagnostics, Vol. 7, No. 4, pp. 3-11, ISSN 1451-1975 (in Serbian) 
Tanikić, D., Manić, M., Radenković, G. \& Mančić, D. (2009). Metal Cutting Process Parameters Modeling: An Artificial Intelligence Approach. Journal of Scientific and Industrial Research, Vol. 68, No. 6, pp. 530-539, ISSN 0022-4456

Tanikić, D., Manić, M. \& Devedžić, G. (2009). Cutting Force Modeling Using the Artificial Intelligence Techniques, Tehnika/Technics, Mechanical engineering, Vol. 58, No. 1, pp. 1-6, ISSN 0461-2531 (in Serbian)

Tanikić, D., Manić, M., Devedžić, G. \& Stević, Z. (2010). Modelling Metal Cutting Parameters Using Intelligent Techniques. Strojniški vestnik - Journal of Mechanical Engineering, Vol. 56, No. 1, pp. 52-62, ISSN 0039-2480

Tanikić, D., Manić, M., Devedžić, G. \& Ćojbašić. Ž. (2010). Modelling of the Temperature in the Chip-Forming Zone Using Artificial Intelligence Techniques. Neural Network World, Vol. 20, No. 2, pp. 171-187, ISSN 1210-0552

Tanikić, D., Marinković V. (2012). Modelling and Optimization of the Surface Roughness in the Dry Turning of the Cold Rolled Alloyed Steel Using Regression Analysis, Journal of the Brazilian Society of Mechanical Sciences and Engineering, accepted for printing, ISSN 1678-5878

Wasserman, P.D. (1993). Advanced Methods in Neural Computing, Van Nostrand Reinhold, New York, USA

Werbos, P. (1974). Beyond regression: New tools for prediction and analysis in the behavioral sciences, PhD thesis, Harvard University

Wright, P.K. (1978). Correlation of tempering effects with temperature distribution in steel cutting tools. Journal of Engineering for Industry, Vol. 100, No. 2, pp. 131-136, ISSN $0022-$ 1817

Young, H.-T. (1996). Cutting temperature responses to flank wear. Wear, Vol. 201, No. 1-2, pp. 117-120, ISSN 0043-1648 